Osborne, T. B. and Mendel, L. B. (1914). J. biol. Chem. 17, 325.

Pearson, R. M. and Smith, J. A. B. (1943). Biochem. J. 37, 153.

Rittenberg, D. and Foster, G. L. (1940). J. biol. Chem. 133, 737.

Robertson, E. C. and Doyle, M. E. (1936). Proc. Soc. exp. Biol., N. Y., 35, 374.

Roche, A. (1934, 1). Bull. Soc. Chim. biol., Paris, 16, 270.

Roche, A. (1934, 2). Skand. Arch. Physiol. 69, 75.

Rose, W. C. (1938). Physiol. Rev. 18, 109.

Rose, W. C., Haines, W. J. and Johnson, J. E. (1942). J. biol. Chem. 146, 683.

Rose, W. C., Haines, W. J., Johnson, J. E. and Warner, D. T. (1943). J. biol. Chem. 148, 457.

Rose, W. C. and Rice, E. E. (1939). Science, 90, 186.

Schenck, E. G. and Wollsehitt, H. (1933, 1). Arch. exp. Path. Pharmak. 170, 151.

Schenck, E. G. and Wollschitt, H. (1933, 2) Arch. exp. Path. Pharmak. 173, 219.

Stare, F. J. and Hegsted, D. M. (1944). Fed. Proc. 3, 120.

Stewart, C. P. (1946). Proc. Nutr. Soc. 4, 225.

Stewart, R. A., Hensley, G. W. and Peters, F. N. (1943). J. Nutrit. 26, 519.

Terroine, E. F. (1936). Quart. Bull. Hlth Org. L.o.N. 5, 427.

Ussing, H. H. (1939). Nature, Lond., 144, 977.

Vaughan, J., Dent, C. and Pitt-Rivers, R. (1945). Proc. R. Soc. Med. 38, 395.

Watson, M. (1937). J. Hyg., Camb., 37, 420.

Whipple, G. H. (1942). Amer. J. med. Sci. 203, 477.

Willcock, E. G. and Hopkins, F. G. (1906-07). J. Physiol. 35, 88.

Williamson, M. B. (1944). J. biol. Chem. 156, 47.

\title{
The Essential Amino-acids
}

\section{Dr. C. P. Stewart (Clinical Laboratory, Royal Infirmary, Edinburgh)}

The proteins present in animal tissues are built up from some twentysix amino-acids, and, inasmuch as the animal can grow only by building more of its various proteins, or maintain itself by making good its continuous protein loss, all these amino-acids may be regarded as essential. By common consent, however, the term essential amino-acid is restricted to those which the animal cannot synthesize from ammonia or some similar source of nitrogen and non-nitrogenous substances derived from fat, carbohydrate, or other amino-acids. Largely because of the experimental methods which have been employed to identify these substances, many authors restrict the term still further to the amino-acids which the animal cannot synthesize in sufficient quantity to promote normal growth. The essential amino-acids are, therefore, indispensable dietary constituents and, in that respect, differ from the vitamins chiefly in being normally ingested in the form of proteins instead of as free chemical entities.

\section{Identification of the Amino-acids Essential to the Growing Rat}

The first clear demonstration that an amino-acid can be an indispensable component of the food was given by Willcock and Hopkins (1906-07). They showed that the protein zein "has no power whatever of maintaining growth in the young animal' but that addition of tryptophane to a diet in which zein was the sole protein diminished the loss of weight and prolonged life though it was unable to allow growth. Zein is deficient in both lysine and tryptophane, and it was later shown by Osborne and Mendel (1914) that addition of these two amino-acids to the zein diet fed to young rats was followed by growth, though neither alone was effective. It was not necessary to add the free amino-acids, equally good results being obtained by adding a protein rich in tryptophane and lysine. These experiments showed, beyond doubt, that both tryptophane voL. 4,1946$]$ 
and lysine must be regarded for the animals used and under the conditions of the experiments as indispensable dietary constituents, i.e., as essential amino-acids.

Before proceeding further, it is perhaps desirable to emphasize this point. One cannot conclude from the experiments just mentioned that lysine and tryptophane are essential amino-acids for all species and under all circumstances. They were shown to be so for the growing rat, but there was no proof that they were needed by the adult rat for maintenance as distinct from growth. Indeed, the results suggested that, whilst tryptophane was essential even for survival, lysine was more particularly required for growth. Nor can it safely be assumed that because these two amino-acids are essential to the growing rat they must be provided in the food of all species. Animals may well vary in their ability to synthesize amino-acids just as they do in their vitamin requirements.

The experiments of Willcock and Hopkins (1906-07) depended on the principle that, if a diet lacking in some known factor failed to allow normal growth and development of experimental animals, and if addition of the missing factor abolished the defect, it could be concluded that the factor concerned was an indispensable constituent of a satisfactory diet, the principle used by Hopkins (1912) in his demonstration of the existence of accessory food factors. Application of this "deficiency method", either by the use of proteins which lacked certain amino-acids or by the chemical removal of definite amino-acids from protein hydrolysates, showed that the list of amino-acids essential to the growing rat must be extended by the addition of histidine (Ackroyd and Hopkins, 1916). The method, however, has strict limitations, for in many cases it is not possible by these means to ensure anything like a complete absence of a given amino-acid from the diet, and evaluation of the experimental data is, consequently, often uncertain. Further, as we now know, one aminoacid which is not, strictly speaking, essential, may spare another which is, and so appear to be an indispensable dietary constituent under certain conditions. Thus experiments by the deficiency method, though yiclding clear cut results for the three amino-acids mentioned, failed to provide unequivocal evidence for, though they suggested, the inclusion of arginine, cystime, and tyrosine, or phenylalanine, in the list of essential amino-acids. Equally, they could only suggest, and not prove, that glycine, proline, hydroxyproline, and the dibasic amino-acids are dispensable.

It goes without saying that the reverse method, of adding extra quantities of an amino-acid to a diet which already contains enough, is useless for the particular purpose under discussion, and a more satisfactory technique could be found only in the feeding of known mixtures of pure amino-acids. Early tentative attempts with this method failed because the number of amino-acids available was far too small and partly, perhaps, because the experiments were made with insufficient boldness and without adequate knowledge of the importance of vitamins. During the past fifteen years, however, systematic researches along these lines have been prosecuted by Rose and his associates, with the result that we can now be much more definite in stating the indispensability or otherwise of the known amino-acids in a variety of conditions. The 
first major discovery made by these workers was that growth-promoting proteins contain at least one essential amino-acid not included among the twenty-one amino-acids then generally accepted as occurring in such proteins (Rose, 1931-32). The search for this, besides demonstrating that isoleucine is indispensable to the rat for growth (Womack and Rose, 1935-36), led to the isolation and identification of $\alpha$-amino- $\beta$-hydroxybutyric acid (McCoy, Meyer and Rose, 1935-36), the actual isomer found being named threonine because of its configuration (Meyer and Rose, 1936), as well as to the final proof that it is an essontial amino-acid for the growing rat and, in all probability, the only one then remaining to. be discovered.

Even before the identification of threonine, Womack and Rose (1934) conclusively proved that, for the growing rat, phenylalanine is an essential dietary constituent, and later they showed that tyrosine is not (Rose, 1938). This disposed of the idea that these two acids are mutually interchangeable (Abderhalden, 1915), but forced the conclusion, originally reached by Embden and Baldes (1913) but controverted by Dakin (1920), Shambaugh, Lewis and Tourtelotte (1931) and others, that phenylalanine is oxidisable to tyrosine in vivo.

The indispensability of isoleucine has already been mentioned, and it was quickly shown that leucine was also essential to the growing rat as, curiously enough, was valine (Rose and Eppstein, 1939), but that norleucine actually had an inhibitory effect on growth (Womack and Rose, 1936).

The conclusions of the earlier workers with respect to lysine, tryptophane and histidine were confirmed, and the position of arginine was clarified. Ackroyd and Hopkins (1916) had supposed arginine and histidine to be interchangeable and were supported in this belief by Geiling (1917), but neither Stewart (1925), who found arginine able to stop loss in weight but unable to support growth, nor Rose and Cox $(1924,1926)$, who found arginine quite ineffective, could confirm this, though they agreed as to the indispensability of histidine. Scull and Rose (1930) demonstrated clearly that arginine can be synthesized by the rat, a result confirmed and extended to other species by the work of Krebs and his associates on urea formation (e.g., Krebs and Henseleit, 1932). Although Scull and Rose (1930) regarded their work as proving the dispensability of arginine, this conclusion is not really justified, as Rose (1938) has pointed out. It was found that on an arginine-free diet, with mixtures of pure amino-acids, growth was less than when arginine was present (unpublished data of Black and Rose, quoted by Rose, 1938). It seems, therefore, that arginine is to be regarded as an indispensable dietary component for normal growth in the rat, but that synthesis may be sufficient for maintenance, or even sub-normal growth, and the amino-acid may, therefore, not be essential to the adult.

On the basis of increased growth rates observed when cystine was added to a diet containing, as the sole protein, 9 per cent. of casein, Osborne and Mendel (1915) regarded cystine as an essential amino-acid, and numerous workers confirmed their results. Jackson and Block (1932), and also Weichselbaum, Weichselbaum, and Stewart (1932) noted, however, that methionine could equally well supplement a low. casein diet. Feeding experiments with pure amino-acid mixtures voL. 4,1946$]$ 
(Womack, Kemmerer and Rose, 1937) then showed that methionine could replace cystine completely, although cystine without methionine was ineffective in inducing growth. Hence methionine is an essential amino-acid and cystine is not, though it stimulates growth when methionine is present in sub-optimal quantities (Womack and Rose, 1941).

The other known amino-acids having been shown to be dispensable (Rose, 1938), it appears that, for the growing rat, the essential aminoacids are threonine, valine, isoleucine, leucine, methionine, lysine, phenylalanine, tryptophane, histidine and arginine. Indeed, a diet containing only these ten amino-acids supported normal growth (unpublished data of Meyer and Rose, quoted by Rose, 1938).

\section{Amino-acids Essential to Other Species and in Other Conditions}

It has already been indicated that the amino-acid requirements of the adult animal for maintenance may differ from those of the young animal for growth. It was suggested at one time, for example, that whereas tryptophane is essential even for maintenance, lysine may be required chiefly, if not solely, for growth. Stewart (1925) found that adult rats, on a diet deficient in, though not entirely devoid of, histidine, maintained weight and allantoin excretion, whereas young rats on the same diet lost weight and excreted greatly reduced amounts of allantoin. Popiel (1940) also found that histidine was not utilized for allantoin formation by the adult rat, though it is by the adult dog, but neither of these series of experiments proved that histidine was completely non-essential to the adult rat. Nitrogen balance experiments, using pure amino-acid mixtures, have been needed to decide maintenance requirements, for quantitative differences in requirements for growth and maintenance are obviously to be expected, and the small quantities of the amino-acid under test remaining in such deficient diets may well have been enough for maintenance though not for growth. The results with arginine, quoted earlier in this paper, form a useful warning.

By feeding pure amino-acid mixtures, Nielsen and Corley (1939) and Wolf and Corley (1939) showed that of the ten amino-acids which had been found essential to the growing rat, only arginine could be omitted from the diet of the adult rat if nitrogen equilibrium was to be maintained. Bauer and Berg (1943) found the same to be true of the mouse which, like the rat, required arginine for growth, and Rose and Rice (1939) found that in so different a species as the dog the same nine amino-acids were indispensable for nitrogen equilibrium, all the others being dispensable. Ruminants present a special problem which has yet to be solved, for the possibility of protein synthesis by micro-organisms in the paunch, suggested as long ago as 1879 (Weiske, Schrodt and Dangel, 1879), has now been proved to occur (e.g., Harris and Mitchell, 1941, 1, 2; see Goss, 1943).

In man, only short experiments on adults seem, so far, to have been made. Rose et al. $(1942,1943)$ showed that a diet, in which 95 per cent. of the nitrogen was supplied by the ten amino-acids known to be essential for the growth of rats, was capable of maintaining nitrogen equilibrium in man. Withdrawal of valine, isoleucine, or phenylalanine produced a negative nitrogen balance, and the same result, though less marked, followed the withdrawal of leucine, threonine, or methionine. A surprising observation was that withdrawal of histidine was without effect. 
More recently, Rose (quoted by Berg, 1944) has demonstrated the indispensability of lysine and tryptophane, as have also Albanese and his colleagues by somewhat different methods (Albanese, Holt, Brumback, Hayes, Kajdi and Wangerin, 1941; Albanese, Holt, Frankston, Kajdi, Brumback and Wangerin, 1943). Using a diet deficient in histidine, Albanese, Holt, Frankston and Irby (1944) have also found that adult men, in these circumstances, lost weight though they remained in nitrogen equilibrium, and have thus thrown doubt on the dispensability of histidine.

The suggestion in all these experiments, for those on man cannot yet be regarded as completed, is that qualitative differences in amino-acid requirements between different mammalian species are relatively small, though there may well be more marked quantitative variations. There is, however, good evidence that the chick differs markedly from mammals in its qualitative as well as in its quantitative needs for amino-acids. Glycine, apparently non-essential to the mammals which have been tested, has been shown to be essential to the growing chick (Almquist and Mecchi, 1940) and arginine appears to be needed for maintenance as well as for growth (Arnold, Kline, Elvehjem and Hart, 1936; Klose, Stokstad and Almquist, 1938). Methionine (Klose and Almquist, 1941), histidine and tryptophane (Almquist and Mecchi, 1941) are needed, and the other amino-acids essential to the rat, lysine, leucine, isoleucine, threonine, valine, and phenylalanine (Almquist, 1942; Almquist and Grau, 1944). A further difference from mammals, however, appears in the finding of the last quoted workers that the chick requires glutamic acid for growth.

It seems that under abnormal conditions amino-acids not ordinarily needed in the diet may become indispensable, though the evidence is not very strong. It certainly suggests that supplies of certain amino-acids from synthesis in vivo may be insufficient when exceptional demands have to be met, and that in these circumstances dietary supplements may be required. Thus Sure (1941) found that cystine was needed by the lactating rat, and less convincing evidence of the same human requirement was found by Daggs (1940). Detoxication processes may at times cause exceptional demands, and excessive intake of benzoate, for example, may be enough to make dietary supplements of glycine essential (Griffith, 1929). The necessity for rapid regeneration of plasma proteins in dogs kept on a low protein diet and rendered hypoproteinaemic by repeated bleeding with return of the red cells has been claimed by Madden, Nachren, Warauch and Whipple (1939) to demand the inclusion in the diet of some source of nitrogen other than the ten amino-acids essential for growth, and glycine was effective. There was some suggestion, too, that cystine was an essential, or at least a desirable, dietary constituent, since on a protein-free diet it, but not methionine, stimulated production of plasma protein for a short time. A similar need for cystine in the simultaneous regeneration of haemoglobin and plasma protein after repeated haemorrhage is implied by the results of Robscheit-Robbins, Miller and Whipple (1943).

Quantitative differences between species have been mentioned, and they certainly seem to exist. But it must be realized that, much as the quantitative evaluation of the essential amino-acid requirements is desired, the problem is difficult. The need for a particular amino-acid is not necessarily for a fixed and absolute amount, but may be conditioned vor. 4, 1946] 
by the supply of other dispensable, as well as essential, amino-acids. Thus Burroughs, Burroughs and Mitchell $(1940,1,2)$ obtained results which suggested that threonine and isoleucine were needed for the utilization of the other essential amino-acids, and there are numerous references in the literature to the sparing action of cystine on methionine. Block (1943), however, has made tentative calculations of the essential amino-acid requirements of man, using, inter alia, data of the per caput food consumption in the U.S.A. during the years 1937-41, and the admittedly incomplete data on the amino-acid composition of individual proteins. In this way he arrived at the following estimate of daily needs: cystine and methionine, $3 \cdot 5$ to $4 \mathrm{~g}$.; arginine, 4 to $5 \mathrm{~g}$.; lysine, 5 to $6 \mathrm{~g}$.; tryptophane, I to $1.24 \mathrm{~g}$.; phenylalanine, 4 to $4.5 \mathrm{~g}$.; threonine, $3.5 \mathrm{~g}$.; leucine, $10 \mathrm{~g}$.; valine, 4 to $4 \cdot 5 \mathrm{~g}$; isoleucine, 3 to $3 \cdot 5 \mathrm{~g}$.

\section{Possible Substitutes for Natural Essential Amino-acids}

It is, of course, obvious that the essential amino-acids cannot be com. pletely synthesized in the animal body from non-protein sources, at any rate in amounts sufficient even for bare maintenance but, in most cases, as with vitamins, the fundamental need seems to be, not for a specific chemical compound, but for some special arrangement of atoms which can be supplied either by the amino-acid, or vitamin, concerned, or by any one of a number of closely related compounds. This, of course, does not render the essential amino-acids any less essential in fact, for it is they, and not the related compounds, which exist in natural foods.

TABLE 1

Ctilization for the Growth of the Rat of Certain forms and Derivatives of Ten Fssential amino-acids

( + indicates that the compound is utilized, - that it is not utilized)

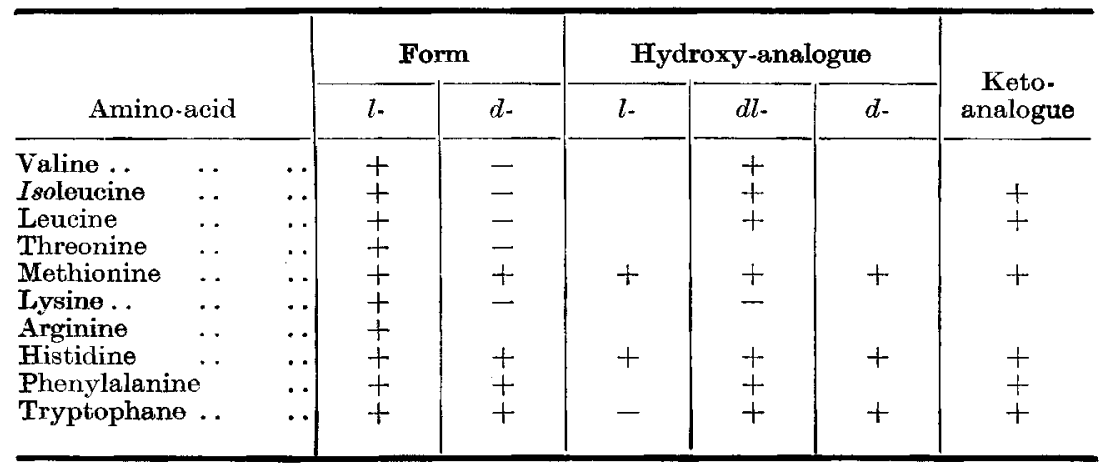

Nevertheless, it is of interest, if only as helping towards our ultimate knowledge of the fate of these substances, that in some cases, though not all, the natural amino-acid can be replaced, more or less successfully, by the optical antipode, the corresponding keto- or hydroxy-acid, the $\mathrm{N}$-acetyl or the $\mathbf{N}$-formyl derivative. This may mean simply that in some cases the active related compounds are convertible, in vivo, to the natural amino-acid. It may mean, however, that some of the essential amino-acids are particularly needed for the synthesis of some important 
compound in the elaboration of which certain other compounds are intermediates. In either case, study of the relationships may be expected to throw light on the reactions involved in the metabolism of the aminoacids concerned. Table 1 summarizes the information about the availability of certain derivatives of the 10 amino-acids essential for the rat.

\section{Special Functions of Essential Amino-acids}

There has always been a tendency to suppose that the essential aminoacids have special functions other than that of forming the raw material for the synthesis of the body proteins. Possibly this has been due in part to the use of the not very happy term "essential", which has conjured up visions of their serving purposes analogous to those served by the vitamins, and a very early suggestion was that they might be the precursors of hormones. Actually, of course, there is no strong a priori reason for regarding the essential amino-acids in this way; they are simply amino-acids, necessary to the animal as are all the others found in animal proteins, but incapable of being synthesized at need. Aminoacids are undoubtedly used for constructive purposes other than the manufacture of proteins; their use in detoxication processes is an obvious example. Some such purposes have long been known, and others are guessed at, but the dispensable as well as the indispensable amino-acids are concerned in these, and it is not unlikely that search for special functions will, in the case of some of the essential amino-acids, be fruitless. Nevertheless, it is part of our task to survey briefly the existing knowledge of the purposes, other than protein synthesis, to which the essential amino-acids are put.

It is natural that, in this respect, we should know most about those amino-acids which, possessing distinctive groups, can be studied with relative ease. The first suggestion of a special function for a known essential amino-acid seems to have been made by Ackroyd and Hopkins (1916), who thought that histidine and possibly arginine might be utilized as precursors of the purines needed by the growing animal in the elaboration of nucleoproteins. The suggestion was made because of the presence in purines and in histidine, but in no other known food constituents, of the iminazole nucleus, combined with the known fact that animals could subsist and grow on a purine-free diet (Benedict, 1915-16). Experiment showed that young rats on a diet deficient in histidine not only failed to grow, or even to maintain their bodyweight, but excreted very much less allantoin that when fed a complete casein hydrolysate, supplemented with tryptophane, or the histidine-deficient diet with added histidine. These results were confirmed by Stewart (1925) and by Rose and Cox (1924, 1926). Popiel (1940) concluded that histidine is a precursor of purines in the dog, though Barnes and Schoenheimer (1943) found no evidence of this in pigeons. These results may reflect real species differences, but the question needs further examination. A second special function of histidine would seem to be in the formation of histamine which occurs in a variety of animal tissues and to which some physiological importance has been ascribed. The origin of histamine is not definitely known, but the experiments of Werle $(1936,1940)$ suggest the de-amination of histidine in the kidney, and Holtz, Credner and Walter (1939) have observed that this reaction may be brought about by other organs.

voL. 4,1946$]$ 
In the case of phenylalanine, the temptation is to regard this aminoacid as the source of all benzene derivatives elaborated in the animal body, and though this may not be entirely justified, there is little doubt that it is the precursor of both adrenaline and thyroxine. The oxidation of phenylalanine to tyrosine has already been mentioned, and its further oxidation to $3: 4$-dihydroxyphenylalanine, which is brought about in plants by tyrosinase, may also occur in animals (Bloch, 1927). The mode of formation of adrenaline from these substances has by no means been completely demonstrated, but it has been shown that various tissues, particularly liver and kidney, contain decarboxylases capable of converting tyrosine and dihydroxyphenylalanine to the corresponding amines (Holtz ei al., 1939; Blaschko, 1942), and that tyramine is converted to adrenaline in the medulla of the adrenal glands (Schuler and Weidemann, 1935). Thyroxine, it was suggested by Harington and Barger (1927), may be formed from two molecules of $3: 5$-di-iodotyrosine by the elimination (in effect) of a molecule of alanine, and di-iodotyrosine may be produced by the direct iodination of tyrosine. In fact, Ludwig and von Mutzenbecher (1939) observed that iodination of certain proteins under specified conditions yielded products containing thyroxine. Von Mutzenbecher (1939) obtained traces of thyroxine by incubating alkaline solutions of di-iodotyrosine in presence of air, and Neuberger (1934) had already obtained di-iodotyrosine by rapid iodination of cold concentrated protein solutions in presence of excess of ammonia. The conversion of di-iodotyrosine to thyroxine thus appears to involve oxidation, a suggestion developed by Johnson and Tewkesbury (1942) and clearly proved by Harington and Pitt-Rivers (1945). It is true that these are all in vitro experiments, but the conditions are such that a similar series of reactions may well be involved in the formation of thyroxine in vivo. A third possible, or probable, special use of phenylalanine is in the formation of melanins. The oxidative changes by which the enzymes of the tyrosinase system of plants bring about the conversion of tyrosine to dihydroxyindole have been thoroughly studied, and though much less is known about the corresponding reactions in animal tissues, it is clear from the work of Bloch (1927) that the melanophores of skin can produce melanins from dihydroxyphenylalanine.

The elucidation of the special functions of methionine may be considered to start with the demonstration by Tucker and Eckstein (1937) that methionine is a lipotropic agent, preventing the fatty infiltration of the liver induced in rats by a diet deficient in choline. This was followed by the observation (Du Vigneaud, Chandler, Moyer and Keppel, 1939) that, although homocystine could not replace methionine in growth experiments on young rats, it could do so in presence of choline. Thus methionine renders dietary choline unnecessary, and choline renders preformed methionine unnecessary provided homocystine is available. The deduction, the validity of which has been confirmed by experiments with deuterio-choline and deuterio-methionine (Du Vigneaud, Chandler, Cohn and Brown, 1940; Du Vigneaud, Chandler and Moyer, 1941; Du Vigneaud, Cohn, Chandler, Schenck and Simmonds, 1941) is that choline can be formed by the transference to some precursor of the methyl group of methionine, and that conversely choline can yield a methyl group to homocystine and so form methionine (Simmonds and Du Vigneaud, 
1942). The experiments of Stetten $(1941,1,2)$ suggest that ethanolamine is the choline precursor. This work lent force to earlier suggestions that the methyl group of methionine might be concerned in creatine synthesis (e.g., Lewis, 1935; Brand, Cahill and Harris, 1935), and in fact Du Vigneaud et al. (1940) working with young rats, and Simmonds and Du Vigneaud (1942) with man, were able to trace the methyl group of methionine to creatine in the tissues and thence to urinary creatinine. The reverse change, the donation of a methyl group by creatine to homocystine in order to form methionine, does not occur ( $\mathrm{Du}$ Vigneaud, Chandler and Moyer, 1941). Bloch and Schoenheimer (1941) have shown clearly that the methyl group of methionine is transferred, for the synthesis of creatine, to guanido-acetic acid, which is itself produced by the interaction of glycine, a non-essential amino-acid, and the amidine group of arginine, an amino-acid essential for growth. Methionine has been shown to be a donor of methyl also in the synthesis of anserine (Schenck, Simmonds, Cohn, Stevens and Du Vigneaud, 1943) and of trigonelline (Huff and Perlzweig, 1943), and Du Vigneaud (1941) has propounded the hypothesis that these reactions may provide the key to the problem of methylation in general.

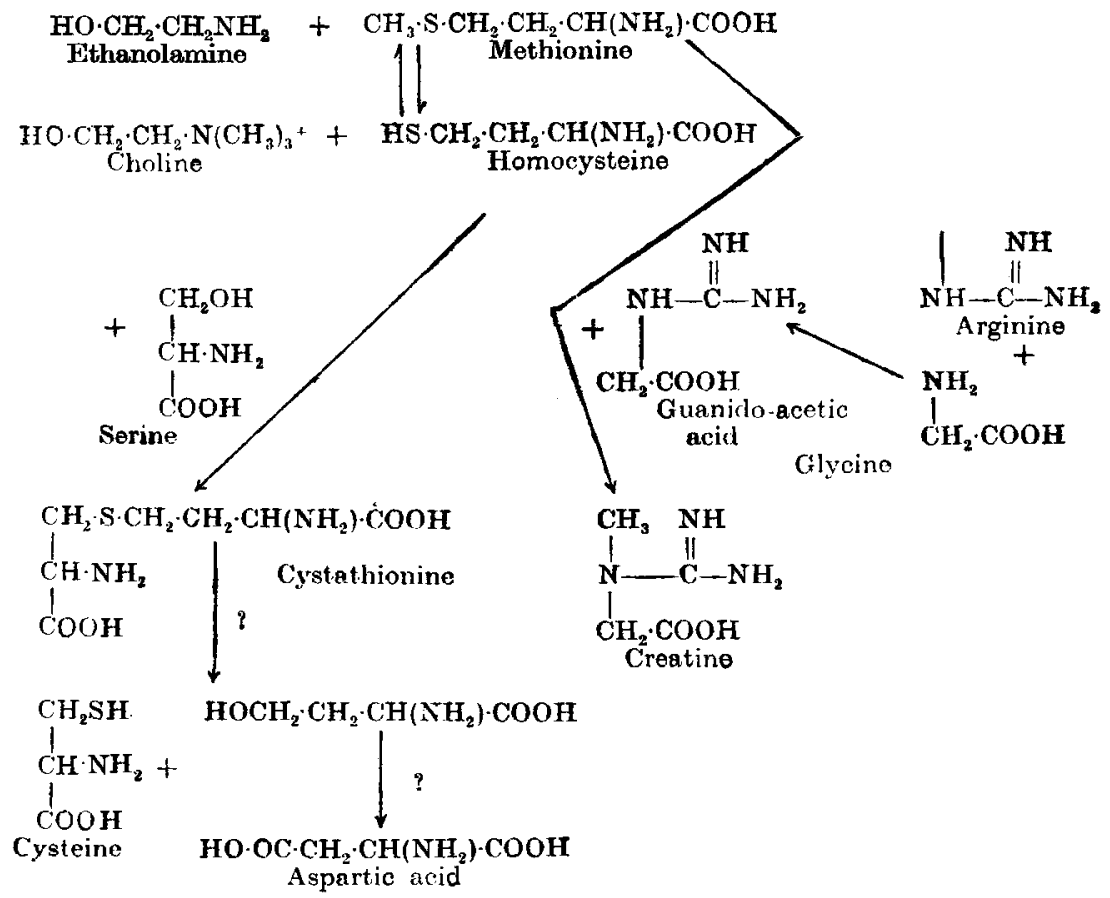

Figute 1. Methionine-Cysteine Relationserrps.

A second important function of methionine is the formation of cysteine, and thence cystine, which, as has been mentioned, is dispensable if the supply of methionine is adequate, but becomes a dietary requisite if there is a deficiency of methionine or if the demands for cysteine are voL. 4,1946 ] 
abnormally high. Methionine can yield cysteine, though the reverse change does not occur. The most probable route seems to be by demethylation of methionine followed by donation of the sulphydryl group of homocysteine to a suitable acceptor, and several hypotheses of this sort bave been advanced. At present this seems possible, since experiments with labelled serine show it to be the acceptor (Stetten, 1942) and that homocysteine reacts with serine to give cystathionine or some similar compound, and that this is hydrolysed with formation of cysteine (Du Vigneaud, Brown and Chandler, 1942). The evidence for this view may be summarized thus: (1) cystathionine, though not isolated from natural sources, is capable of supporting growth and replacing cystine in the diet; (2) under anaerobic conditions, liver slices convert $l$-homocysteine to cysteine in the presence of $l$-serine but not of ammonia and pyruvic acid; (3) methionine plus serine behaves similarly, though it is very much less effective; (4) the nitrogen of serine can be identified in cysteine formed in vivo. In this brief account, much of the evidence has necessarily been omitted, and only key changes have been quoted. There is, for example, the question of whether, since homocysteine has never been isolated from natural sources, and since it is not de-aminated by liver slices, the metabolically active substance is not $\alpha$-keto- $\gamma$-methylthiobutyric acid, which can replace methionine in the diet, rather than methionine itself. This could give the keto-analogue of cystathionine which, on hydrolysis, could give cysteine and $\alpha$-keto- $\gamma$-hydroxybutyric acid. All, however, that is certain is that methionine is concerned in cysteine synthesis and that serine is the sulphydryl acceptor.

The utilization of arginine in the formation of urea by its participation in the ornithine cycle (Krebs and Henseleit, 1932) is fairly generally accepted as representing an important, though not necessarily the sole, mode of formation of urea. It must therefore be considered as a special function of an amino-acid essential at least for normal growth, though it does not seem likely to be the key function of arginine. Acceptance of the ornithine cycle theory of urea formation is based on the following findings: (1) arginase hydrolyses arginine to urea and ornithine; (2) tissues which produce urea freely (liver and kidney) in those species in which urea is the main end product of nitrogen metabolism contain arginase (Hunter and Dauphinee, 1925); (3) ornithine catalyses the production of urea from ammonia by liver slices or in the intact perfused liver (Trowell, 1941); (4) citrulline, which has a similar effect, is produced during the accelerated urea production in presence of ornithine (Gornall and Hunter, 1943); (5) studies with isotopic nitrogen show the preferential accumulation of $\mathbf{N}^{15}$ in arginine of the liver proteins (Schoenheimer, Ratner and Rittenberg, 1939, 1, 2). Numerous objections to this theory have been raised (e.g., Trowell, 1941; Bach, 1939; Borsook and Dubnoff, 1941), but the replies of Krebs (1942) and of Gornall and Hunter (1943) dispose of these in such a way as to leave the ornithine cycle acceptable as the most probable explanation at present available of one method both of arginine synthesis and of urea formation.

No evidence of special function has been adduced for the other essential amino-acids. This, of course, does not mean that they have no special functions. It may well be, however, that these substances, required for protein synthesis if for nothing else, merely possess structural peculiarities 
which render their synthesis in the animal body difficult or impossible. Thus, of those not accounted for in the preceding discussion, tryptophane contains the indole nucleus substituted in the 3 position and this arrangement may not be synthesizable by the animal which, however, appears to be capable of obtaining $5: 6$-dihydroxy-indole-2-carboxylic acid from 3 : 4-dihydroxy-phenylalanine. Also included are certain aliphatic amino-acids, and it is noteworthy that the essential amino-acids of this class are those with branched chains. Of the di-amino-acids, some specific function has been ascribed to histidine and arginine; the third, lysine, is peculiar in that its $\alpha$-amino group is singularly difficult to remove (Felix and Naka, 1940) and it is equally difficult to form lysine by amination of the corresponding keto-acid (Foster, Rittenberg and Schoenheimer, 1938; Schoenheimer et al., 1939, 1, 2).

In general, lack of an essential amino-acid produces no specific symptoms such as are associated with vitamin deficiencies, but it may be significant of a specific function yet undiscovered that deprivation of valine causes, in addition to the usual loss of weight, profound nutritive failure and lack of appetite, a curious sensitivity to touch and a lack of co-ordination in movement (unpublished data of Eppstein and Rose, quoted by Rose, 1938). Similarly, lysine deficiency in man has been described as producing nausea, dizziness and a hypersensitivity to metallic sounds (Albanese et al., 1943), arginine deficiency, also in man, has been said to result in decreased production of spermatozoa (Holt, Albanese, Shettles, Kajdi and Wangerin, 1942), and cystine deficiency in rats was claimed by Weichselbaum (1935) to produce a specific syndrome in which liver damage was prominent.

\section{RHFHERENCES}

Abderhalden, E. (1915). Hoppe-Seyl. Z. 96, 1.

Ackroyd, H. and Hopkins, F. G. (1916). Biochem. J. 10, 551.

Albanese, A. A., Holt, L. E. (Jr.), Brumback, J. E. (Jr.), Hayes, M., Kajdi, C. N. and Wangerin, D. M. (1941). Proc. Soc. exp. Biol., N.Y., 48, 728.

Albanese, A. A., Holt, L. E. (Jr.), Frankston, J. E., Kajdi, C. N., Brumback, J. E. (Jr.), and Wangerin, D. M. (1943). Proc. Soc. exp. Biol., N.Y., 52, 209.

Albanese, A. A., Holt, L. E. (Jr.), Frankston, J. E. and Irby, V. (1944). Johns Hopk. Hosp. Bull. 74, 251.

Almquist, H. J. (1942). Fed. Proc. 1, 269.

Almquist, H. J. and Grau, C. R. (1944). J, Nutrit. 28, 325.

Almquist, H. J. and Mecchi, E. (1940). J. biol. Chem. 135, 355.

Almquist, H. J. and Mecchi, E. (1941). Proc. Soc. exp. Biol., N.Y., 48, 526.

Arnold, A., Kline, O. L., Elvehjem, C. A. and Hart, E. B. (1936). J. biol. Chem. $116,699$.

Bach, S. J. (1939). Biochem. J. 33, 1833.

Barnes, F. W. (Jr.) and Schoenheimer, R. (1943). J. biol. Chem. 151, 123.

Bauer, C. D. and Berg, C. P. (1943). J. Nutrit. 26, 51.

Benedict, S. R. (1915-16). Harvey Lect. 11, 346.

Berg, C. P. (1944). Annu. Rev. Biochem. 13, 239.

Blaschko, H. (1942). J. Physiol. 101, 337.

Bloch, B. (1927). Handbuch der Haut- und Geschlechtslkrankheiten. Berlin: Springer.

Bloch, K. and Schoenheimer, R. (1941). J. biol. Chem. 138, 155.

Block, R. J. (1943). Yale J. biol. Med. 15, 723.

Borsook, H. and Dubnoff, J. W. (1941). J. biol. Chem. 141, 717.

Brand, E., Cahill, G. F. and Harris, M. M. (1935). J. biol. Chem. 109, 69.

Burroughs, E. W., Burroughs, H. S. and Mitchell, H. H. (1940, 1). J. Nutrit. 19,363 .

Burroughs, E. W., Burroughs, H. S. and Mitchell, H. H. (1940, 2). J. Nutrit. 19,385 .

vot. 4,1946$]$ 
Daggs, R. G. (1940). Amer. J. Obstet. Qynec. 40, 457.

Dakin, H. D. (1920). J. biol. Chem. 44, 499.

Du Vigneaud, V. (1941). Biol. Symp. 5, 234.

Du Vigneaud, V., Brown, G. B. and Chandler, J. P. (1942). J. biol. Chem. 143, б9.

Du Vigneaud, V., Chandler, J. P., Cohn, M. and Brown G. B. (1940). J. biol. Chem. 134, 787.

Du Vigneaud, V., Chandler, J. P. and Moyer, A. W. (1941). J. biol. Ohem. 139, 917.

Du Vigneaud, V., Chandler, J. P., Moyer, A. W. and Keppel, D. M. (1939). J. biol. Chem. 128, cviii; 131, 57.

Du Vigneaud, V., Cohn, M., Chandler, J. P., Schenck, J. R. and Simmonds, S. (1941). J. biol. Chem. 140, 625 .

Finbden, G. and Baldes, K. (1913). Biochem. Z. 55, 301.

Felix, K, and Naka, S. (1940). Hoppe-Zeyl. Z. 264, 123.

Foster, G. L., Rittenberg, D. and Schoenheimer, R. (1938). J. biol. Chem. 125, 13.

Geiling, E. M. K. (1917). J. biol. Chem. 31, 173.

Gornall, A. G. and Hunter, A. (1943). J. biol. Chem. 147, 593.

Goss, H. (1943). Nutr. Abstr. Rev. 12, 531.

Griffith, W. H. (1929). J. biol. Chem. 82, 415.

Harington, C. R. and Barger, G. (1927). Biochem. J. 21, 169.

Harington, C. R. and Pitt-Rivers, R. V. (1945). Biochem. J. 39, 157.

Harris, L. E. and Mitchell, H. H. (1941, 1). J. Nutrit. 22, 167.

Harris, L. Es and Mitchell, H. H. (1941, 2). J. Nutrit. 22, 183.

Holt, L. E. (Jr.), Albanese, A. A., Shettles, L. B., Kajdi, C. and Wangerin, D. M. (1942). Fed. Proc. 1, 116.

Holtz, P., Credner, K. and Walter, H. (1939). Hoppe-Seyl. Z. 262, 111.

Hopkins, F. G. (1912). J. Physiol. 44, 425.

Huff, J. W. and Perlzweig, W. A. (1943). J. biol. Chem. 150, 395.

Hunter, A. and Dauphinee, J. A. (1925). Proc. roy. Soc. (B.), 97, 227.

Jackson, R. W. and Block, R. J. (1932). J. biol. Chem. 98, 465.

Johnson, T. B. and Tewkesbury, L. B. (1942). Proc. nat. Aead. Sci., Wash., $28,73$.

Klose, A. A. and Almquist, H. J. (1941). J. biol. Chem. 138, 467.

Klose, A. A., Stokstad, F. L. R. and Almquist, H. J. (1938). J. biol. Chem. 123, 691.

Krebs, H. A. (1942), Biochem. J. 36, 758.

Krebs, H. A. and Henseleit, K. (1932). Hoppe-Seyl. Z. 210, 33.

Lewis, H. B. (1935). J. Nutrit. 10, 99.

Ludwig, W. and Mutzenbecher, P. von (1939). Hoppe-Seyl. Z. 258, 195.

McCoy, R. H., Meyer, C. F. and Rose, W. C. $(1935-36)$. J. biol. Chem. 112, 283.

Madden, S. C., Nachren, W. A., Warauch, G. S. and Whipple, G. H. (1939). J. exp. Med. 69, 721 .

Meyer, C. E. and Rose, W. C. (1936). J. biol. Chem. 115, 721.

Mutzenbecher, P. von (1939). Hoppe-Seyl. Z. 261, 253.

Neuberger, A. (1934). Biochem. J. 28, 1982.

Nielsen, E. K. and Corley, R. C. (1939). Amer. J. Physiol. 126, 223.

Osborne, T. B. and Mendel, L. B. (1914). J. biol. Chem. 17, 325.

Osborne, T. B. and Mendel, L. B. (1915). J. biol. Chem. 20, 351.

Popiel, L. V. (1940). J. Physiol. U.S.S.R. 29, 362.

Robscheit-Robbins, F. S., Miller, L. L. and Whipple, G. H. (1943). J. exp. Med. $77,375$.

Rose, W. C. (1931-32). J. biol. Chem. 94, 155.

Rose, W. C. (1938). Physiol. Rev. 18, 109.

Rose, W. C. and Cook, K. G. (1925). J. biol. Chem. 64, 325.

Rose, W. C. and Cox, G. J. (1924). J. biol. Chem. 61, 747.

Rose, W. C. and Cox, G. J. (1926). J. biol. Chem. 68, 217.

Rose, W. C. and Eppstein, S. H. (1939). J. biol. Chem. 127, 677.

Rose, W. C., Haines, W. J. and Johnson, J. E. (1942). J. biol. Chem. 146, 683.

Rose, W. C., Haines, W. J., Johnson, J. E. and Warner, D. T. (1943). J. biol. Chem. 148, 457 .

Rose, W. C. and Rice, E. E. (1939). Science, 90, 186.

Schenck, J. R., Simmonds, S., Cohn, M., Stevens, C. M. and Du Vigneaud, V. (1943). J. biol. Chem. 149, 355.

Schoenheimer, R.; Ratner, S. and Rittenberg, D. (1939,1). J. biol. Chem. 127, 333.

Schoenheimer, R., Ratner, S. and Rittenberg, D. (1939, 2). J. Jiol. Chem. 130, 703. 
Schuler, W. and Weidemann, A. (1935). Hoppe-Seyl. Z. 233, 235.

Seull, C. W. and Rose, W. C. (1930). J. biol. Chem. 89, 109.

Shambaugh, N. F., Lewis, H. B. and Tourtelotte, D. (1931). J. biol. Chem. 92, 499 ,

Simmonds, S. and Du Vigneaud, V. (1942). J. biol. Chem. 146, 685.

Stetten, D. $(1941,1)$. J. biol. Chem. 138, 437.

Stetten, D. (1941, 2). J. biol. Chem. 140, 143.

Stetten, D. (1942). J. biol. Chem. 144, 501.

Stewart, C. P. (1925). Biochem. J. 19, 1101.

Sure, B. (1941). J. Nutrit. 22, 491.

Trowell, O. A. (1941). J. Physiol. 100, 432.

Tucker, H. T. and Eckstein, H. C. (1937). J, biol. Chem. 121, 479.

Weichselbaum, T. E. (1935). Quart. J. exp. Physiol. 25, 363.

Weichselbaum, T. E., Weichselbaum, M. B. and Stewart, C. P. (1932). Nature, Lond., 129, 795,

Weiske, H., Schrodt, M. and Dangel, S. V. (1879). Z. Biol. 15, 261.

Werle, E. (1936). Biochem. Z. 288, 293.

Werle, E. (1940). Biochem. Z. 304, 201.

Willcock, E. G. and Hopkins, F. G. (1906-07). J. Physiol. 35, 88.

Wolf, P. A. and Corley, R. C. (1939). Amer. J. Physiol. 127, 589.

Womack, M., Kemmerer, K. S. and Rose, W. C. (1937). J. biol. Chem. 121, 403.

Womack, M. and Rose, W. C. (1934). J. biol. Chem. 107, 449.

Womack, M. and Rose, W. C. (1935-36). J. biol. Chem., 112, 275.

Womack, M. and Rose, W. C. (1936). J. biol. Chem. 116, 381.

Womack, M. and Rose. W. C. (1941). J. biol. Chem. 141, 375.

\section{The Therapeutic Use of Protein Hydrolysates}

\section{Dr. A. B. Anderson (Glasgow Royal Infirmary)}

There are several recent reviews dealing with various aspects of the use of protein hydrolysates (Cuthbertson, 1944; Elman, 1944, 1945; Gaunt, 1944), and this paper is to some extent a summary of the present position. No attempt has been made to review the literature completely. The remarks are confined to the work on human beings.

Protein hydrolysates are a very recent addition to the therapeutic armamentarium, and it is surprising that these preparations did not come into use earlier, when one considers the obvious theoretical advantages of the hydrolysates as easily assimilated non-antigenic material, and the fact that various digests of proteins have been used for many years as nutrients for bacterial growth, e.g., a tryptic digest of casein (Cole and Onslow, 1916). It was not until 1938 that a preparation of hydrolysed protein was administered intravenously to human beings by Eilman and Weiner (1939), although in 1889 an alkaline digest of casein had been injected intravenously into animals (Neumeister, 1889).

\section{Indications for Therapy}

The theoretical indications for the use of a protein hydrolysate may be considered to be states of protein deficiency or threatened deficiency following:

(1) Inability to ingest protein food because of some gastro-intestinal disease, e.g., intestinal obstruction or persistent vomiting;

(2) Starvation;

(3) Inability to ingest sufficient protein to make up for excessive loss from the body, e.g., in severe burns;

voL. 4,1946$]$ 